\title{
Quantifying the Effects of Patent Protection on Innovation, Imitation, Growth, and Aggregate Productivity ${ }^{\dagger}$
}

\author{
Pedro Bento \\ Texas A\&M University*
}

August 2015

Abstract

I develop a general equilibrium model in which patent protection affects sequential innovation, original innovation, and imitation. Protection increases the cost of working around existing patents, but imposes costs disproportionately for innovators and imitators. Depending on these relative costs, protection can in theory increase or decrease markups, imitation, longrun growth, and aggregate productivity. Using data from several different sources, I calibrate the model and quantitatively assess the effects of patent protection in practice. I find that weakening protection in the U.S. would lead to no change in markups and imitation, no change in long-run growth, a more than doubling of the number of firms, and an increase in aggregate productivity of 11 percent.

Keywords: patent protection, firm size, productivity, innovation, imitation, competition. JEL codes: O1, O3, O4.

\footnotetext{
${ }^{\dagger}$ I would like to thank Margarita Duarte, Gueorgui Kambourov, Matt Mitchell, Adam Nowak, Diego Restuccia, Roberto Samaniego, Xiaodong Zhu, and seminar participants at the University of Cambridge, the University of Pittsburgh, the University of Toronto, and West Virginia University for valuable comments and suggestions.

*Texas A\&M University, Department of Economics, 3056 Allen Building, 4228 TAMU, College Station, TX 77843. E-mail: pbento@tamu.edu.
} 


\section{Introduction}

Does patent protection encourage innovation? If so, through what mechanisms? Patent protection is generally thought to encourage innovation by discouraging imitation, and several theoretical papers have investigated the optimal trade-off between the level of innovation and the prices faced by consumers. But empirical studies have been hard-pressed to find a robust positive relationship between protection and innovation, ${ }^{1}$ and evidence of any relationship between patent protection and imitation or markups has been suprisingly absent. Nevertheless, even if the aggregate level of innovation is independent of the strength of patent protection, the allocation of innovative inputs may not be. For example, Chu, Cozzi, and Galli (2012) show that if patent protection imposes costs on sequential innovators (who attempt to improve on patent-protected products), then stronger protection may induce a reallocation from sequential to original innovation. Although growth may decrease due to slower quality improvements, welfare may still be higher due to an increase in the number of varieties available to consumers.

In this paper I develop a general equilibrium model that allows for patent protection to work through all of these mechanisms, without any restrictive assumptions about the qualitative effects of patent protection on original innovation, sequential innovation, or imitation. In the model, innovative firms choose between creating original products (thereby creating new product markets) or improved versions of existing products. Successful innovators enjoy monopoly profits at first, but then face competition from imitators. Eventually, a new round of sequential innovation occurs in each market, and an incumbent may either retain its incumbent status or lose the market to a new innovator. Imitators must work around existing patents, so protection increases the cost of imitation. At the same time I allow for the possibility that protection increases the cost of innovators, who must also work around existing patents. The effects of patent protection on original innovators, sequential innovators, and imitators depend on the

\footnotetext{
${ }^{1}$ For example, all of the following papers report either less innovation or no effect on innovation from stronger patent protection: Sakakibara and Branstetter (2001); Qian (2007); Boldrin and Levine (2008, 2013); Lerner (2009); Moser and Voena (2012); Moser (2013).
} 
relative costs imposed by patent protection on each group. For example, if protection imposes a larger burden on imitators than on innovators, then stronger protection discourages imitation and increases markups. If protection increases the cost of innovation for sequential innovators more than original innovators, then stronger protection discourages quality improvements and lowers long-run growth.

To gauge the impact of patent protection in practice, I take the model to the data. I obtain information about the relative costs of protection on innovators and imitators by using the model to interpret empirical relationships between the strength of patent protection and markups, the number of firms, and the ratio of original to sequential innovations. The data suggests that there is no significant relationship between the strength of patent protection and markups, nor between protection and the ratio of original to sequential innovators. Interpreted through the model, these empirical results suggest that protection increases the costs of innovators and imitators proportionately. This implies that stronger protection should result in a decrease in original innovation and fewer product markets, which increases the potential revenue of each market just enough to leave the value of entry constant for imitators and sequential innovators. Using the calibrated model to quantify the effects of patent protection, I estimate that weakening protection in the U.S. would lead to no change in imitation and markups, no change in long-run growth, a more than doubling of the number of firms, and an increase in aggregate productivity of 16 percent.

The model developed in this paper is similar to Chu, Cozzi, and Galli (2012), who model patent protection as a transfer of revenue from sequential innovators to original innovators in a general equilibrium setting, but the present model differs in three important ways. First, the model is cast in discrete time, which more easily allows for an endogenous number of firms (as in Bento, 2014). ${ }^{2}$ This allows me to exploit recently constructed data on the number of firms across countries (Bento and Restuccia, 2015). Second, I allow for imitation, generating

\footnotetext{
${ }^{2} \mathrm{Chu}$, Cozzi, and Gali (2012) extend Grossman and Helpman (1991), and as a result the number of firms in their model is indeterminate.
} 
testable implications for markups. Third, I assume patent protection imposes costs on potential patent infringers, who must use up resources to work around any relevant patents. This last assumption is consistent with the findings of both Mansfield, Schwartz, and Wagner (1981) and Zander and Kogut (1995), who report that patents are virtually never licenced to potential competitors.

Scotchmer (1991) analyzes optimal patent policy when innovation is sequential, as do a large number of subsequent papers like O'Donoghue and Zweimüller (2004), Hopenhayn, Llobet, and Mitchell (2006), Bessen and Maskin (2009), and Acemoglu and Akcigit (2012). In each of these papers the number of innovators is either fixed or indeterminate, and imitation is neglected. Segerstrom (1991) and Helpman (1993) consider imitation in models of sequential innovation, but do not account for different types of innovation as I do here. As extensions of Grossman and Helpman (1991), their models are also silent about the determinants of the number of firms. Bento (2014) models sequential innovation with an endogenous number of firms, but does not account for different types of innovation or imitation.

By quantifying the effects of patent protection on the number of firms, this paper contributes to the growing literature attempting to explain differences in firm size (the inverse of the number of firms per worker) across countries. See, for example, Bhattacharya, Guner, and Ventura (2013), Hsieh and Klenow (2014), and Bento and Restuccia (2015), who analyse the effects of misallocation on firm size and other outcomes.

Another contribution of this paper is in developing a model with endogenous markups where both markups and the number of firms are independent of population. This is consistent with the findings of Bento and Restuccia (2015), but in direct contrast to all current models with endogenous markups and endogenous firm entry. ${ }^{3}$

\footnotetext{
${ }^{3}$ As far as I know. For example, see Melitz and Ottaviano (2008), Desmet and Parente (2010), Peters (2013), and Edmond, Midrigan, and Xu (forthcoming). In each of these models a larger population increases the size of each market, which encourages entry. More entry reduces markups which stops the number of firms from increasing proportionately with population. As a result, these models imply that the number of firms per worker should be lower in more populous economies.
} 
In the next section I describe the model, characterize equilibrium, and discuss its key implications. In Section 3 I calibrate the model and show that weakening patent protection in the U.S. would increase productivity. The final section concludes.

\section{Model}

Consider an economy in which time is discrete and a final good is produced using a variety of inputs from a representative intermediate industry. Intermediate firms (hereafter refered to as 'firms') produce these inputs one-for-one using labor. The final good can be used both for consumption and to finance the introduction of new products, and will also act as the numéraire. ${ }^{4}$ There are a large number of potential innovating firms, any of which can choose to introduce an improved version of an existing product or create an original product. There are also a large number of potential imitators, any of which can choose to create an exact copy of an existing product. I assume products can be imitated after one period, but improved only after two periods. ${ }^{5}$ In addition, each product market faces an exogenous probability of destruction every two periods (before each new round of innovation), so new product markets (spawned by original products) continue to be created along the balanced growth path (BGP). I study the stationary decentralized equilibrium of the economy along a BGP, in which firms take the economy-wide wage, growth rate, and interest rate as given, and free entry ensures the value of entry for all innovators and imitators is driven to zero. I begin by describing the environment in more detail.

\footnotetext{
${ }^{4}$ Given the lack of capital in the model, output per capita will be equivalent to aggregate productivity. I therefore use 'output per capita' and 'aggregate productivity' interchanegably.

${ }^{5}$ This is consistent with Mansfield, Schwartz, and Wagner (1981) and Zander and Kogut (1995), who find that imitating a product takes just over half the time required to create the product in the first place (on average).
} 


\section{$2.1 \quad$ Environment}

There is a continuum of identical consumers of constant measure $L$, each supplying one unit of labor to intermediate firms. Each consumer values only consumption $(C)$ and has a constant discount factor $\beta \in(0,1)$. Preferences over the stream of consumption in each period are described by the following log-utility function;

$$
\sum_{t=0}^{\infty} \beta^{t} \log \left(C_{t}\right)
$$

The market for final output is perfectly competitive, with a representative firm using inputs from a representative intermediate industry to produce output according to the following production function; ${ }^{6}$

$$
Y=\left(\int_{0}^{M}\left(\sum_{n=1}^{N_{m}} A_{n, m}^{\frac{1-\alpha}{\alpha}} y_{n, m}\right)^{\alpha} d m\right)^{\frac{1}{\alpha}}
$$

where $m$ indexes a continuum of product markets of measure $M, y_{n, m}$ is the quantity of input $m$ demanded from firm $n, A_{n, m}$ is the quality of input $m$ produced by firm $n$, and $\frac{1}{1-\alpha}>1$ is the constant elasticity of substitution between differentiated product markets.

Different products within a product market are perfectly substitutable, and I make the following two assumptions with respect to firms' price and quantity decisions. First, if multiple firms produce an input using the same quality $A_{m}$, then they engage in cournot competition, choosing output while taking the output of competitors as given. Second, if firms are heterogeneous with respect to quality, then the firm with the $1^{\text {st }}$-best quality $A_{n, m}=A_{[1], m}$ can commit to charging a limit price if any rivals attempt to produce, ensuring only the best firm in the market produces in equilibrium. ${ }^{7}$

\footnotetext{
${ }^{6}$ Throughout the paper, I omit the time subscript unless clarity requires it.

${ }^{7}$ In Bento (2014) I consider a market where the best firm charges a price equal to the marginal cost of its closest rival (adjusted for quality) in equilibrium (i.e., limit pricing). Incorporating this in the present model would complicate the analysis without adding any insights to those already discussed in Bento (2014).
} 
Finally, I assume each product market is destroyed with probability $\lambda$ every two periods (before each round of innovation).

\subsection{Innovation}

\subsubsection{Sequential Innovations}

At the beginning of each period, after any exogenous market death has occured, potential innovators can choose to undertake the investment necessary to create and introduce an improved product into any market (as long as the current incumbent's product has existed for two periods). Denote the $1^{\text {st }}$-best quality in period $t-2$ in market $m$ by $A_{[1], m, t-2}$. Any firm $i$ that chooses to incur the cost of introducing an improved version of product $m$ in period $t$ receives a quality equal to $A_{i, m, t}=A_{[1], m, t-2} \cdot\left(1+h_{i, m, t}\right)$, where $h_{i} \in(0, \bar{h})$ is randomly drawn from a bounded distribution. There is a fixed cost associated with creating and introducing an improved product, which must be incurred before $h$ is realized. For the incumbent, this fixed

cost is equal to $\frac{Y_{t}}{L} \cdot \Psi_{m, t-2} \cdot c_{s}^{\prime}, c_{s}^{\prime}>0$. For all other sequential innovators, the cost of creating and introducing an improved product is $\frac{Y_{t}}{L} \cdot \Psi_{m, t-2} \cdot c_{s} \cdot \rho, c_{s}>c_{s}^{\prime} . \Psi_{m, t}$ is defined as;

$$
\begin{gathered}
\Psi_{m, t-2} \equiv \frac{A_{[1], m, t-2}}{\bar{A}_{[1], t-2}^{i n n}}, \\
\bar{A}_{[1], t-2}^{i n n} \equiv \frac{1}{M_{t-2}^{i n n}} \int_{0}^{M_{t-2}^{i n n}} A_{[1], m^{i n n}, t-2} d m^{i n n},
\end{gathered}
$$

where $M_{t-2}^{i n n} \subset M_{t-2}$ is the subset of markets in which innovation occurred in period $t-2$, indexed by $m^{i n n}$. Having the cost of innovation scale up with aggregate output per capita is consistent with the findings of Bollard, Klenow, and Li (2014). Making innovation more costly in higher-quality markets is intuitive, and also serves to ensure that innovating firms face the same decision in different markets. The scalar $\rho \geq 1$ represents the strength of patent protection. The stronger is protection, the more costly it is to innovate around an incumbent's patent. An 
incumbent need not work around its own patent, and even in the absence of protection incurs a lower cost of innovation.

\subsubsection{Original Innovations}

At the beginning of each period, potential innovators can also create an original product, thereby creating a new product market. I assume that original innovators must incur a cost of $\frac{Y}{L} \cdot c_{o} \cdot \rho^{\phi}$, $c_{o}>0, \phi>0$, where $\phi>1$ implies that patent protection imposes a larger cost on original innovators relative to sequential innovators, and $\phi<1$ implies the opposite. When an original product is created, it acquires a quality $A_{o}$ equal to the average quality across producers in innovating markets $\bar{A}_{[1], t}^{i n n}$.

\section{$2.3 \quad$ Imitation}

At the beginning of each period, potential imitators may choose to imitate an incumbent's product and compete in the same market (as long as the incumbent's product has existed for at least one period). To introduce a copy of the best firm's product in market $m$ in period $t$,

an imitator must incur a fixed cost equal to $\frac{Y_{t}}{L} \cdot \Psi_{m, t-1} \cdot \hat{c} \cdot \rho^{\gamma}, \hat{c}>0, \gamma>0$, where $\Psi_{m, t-1}$ and $\rho$ are defined as above. $\gamma>1$ implies that patent protection increases the cost of imitation more than the cost of sequential innovation, while $\gamma<1$ implies the opposite. An imitator receives the same quality as the incumbent.

\subsection{Equilibrium}

I focus on the stationary decentralized equilibrium of the model, and make two simplifying assumptions about the economy at time zero. First, I assume markets that initially feature imitation outnumber markets with sequential innovations by a factor of $1 /(1-\lambda)$. This ensures 
that in every period, after new products have been created, half of all markets will feature imitation. Second, I assume the initial sequential innovators improve on $A_{[1], m,-2}=1 /(1+$ $\left.\mathbb{E}\left[h_{[1]}\right]\right)^{1 / 2}$, while initial imitators have a quality equal to $A_{[1], m, 0}=1$, where $\mathbb{E}\left[h_{[1]}\right]$ is the average quality improvement across markets with sequential innovation on the balanced growth path. Together, these assumptions ensure that the growth rate is constant from period to period. In such an equilibrium, given these assumptions, the interest rate $r$ and growth rate of aggregate output are constant, as is the measure of product markets $M$, and the wage $w$ grows at the same rate as aggregate output. In addition, the assumptions made about the environment above will ensure a constant number of both innovators $N^{i n n}$ and imitators $N^{i m}$ per market over time. I begin by describing the decision problems of each agent, and then define and solve for the stationary equilibrium.

\subsubsection{Consumer}

In each period consumers choose both consumption and savings, and the only vehicle for savings is the purchase of equity in innovating firms, earning a rate of return of $r .{ }^{8}$ The representative consumer's problem in each period $t^{\prime}$ is therefore to choose consumption $C$ and savings $S$ for each period $t \geq t^{\prime}$, given $w, r$, and $g$, to maximize;

$$
\sum_{t=t^{\prime}}^{\infty} \beta^{t} \log \left(C_{t}\right), \quad \text { s.t. } C_{t}+S_{t} \leq w_{t^{\prime}}(1+g)^{t-t^{\prime}}+S_{t-1}(1+r) .
$$

The first order conditions for this problem imply the following interest rate;

$$
r=\frac{1+g}{\beta}-1 .
$$

\footnotetext{
${ }^{8}$ I take it as given that each consumer will diversify across all innovating firms, as every firm shares the same expected value before innovating.
} 


\subsubsection{Final-Good Producer}

In each period, the final-good producer takes the prices of all intermediate inputs as given, and demands inputs from each intermediate product market to maximize profits;

$$
Y-\int_{0}^{M} \sum_{n=1}^{N_{m}} P_{n, m} y_{n, m} d m
$$

where $Y=\left(\int_{0}^{M}\left(\sum_{n=1}^{N_{m}} A_{n, m}^{\frac{1-\alpha}{\alpha}} y_{n, m}\right)^{\alpha} d m\right)^{\frac{1}{\alpha}}$ and $P_{n, m}$ is the price of input $m$ from firm $n$. The first order conditions for the final-good firm's problem imply the following inverted demand function for markets in which imitation has not yet taken place;

$$
P_{[1], m}=Y^{1-\alpha} A_{[1], m}^{1-\alpha} y_{[1], m}^{\alpha-1},
$$

and the following inverted demand function after imitators have entered a market;

$$
\hat{P}_{m}=Y^{1-\alpha} A_{[1], m}^{1-\alpha}\left(\hat{y}_{[1], m}+\sum_{n=1}^{N_{m}^{i m}} \hat{y}_{n, m}\right)^{\alpha-1}
$$

where $N_{m}^{i m}$ is the number of imitators in market $m$ and $\hat{y}_{n, m}$ is the output of imitator $n$.

\subsubsection{Intermediate Firms}

In markets where sequential innovations are introduced, all but the highest-quality firm in each product market will choose not to produce. Producers face the downward-sloping demand curves implied by the final-good firm's problem above, and demand labor $y_{[1], m}$ given the wage $w$, to maximize operating profits;

$$
\pi_{[1], m}=P_{[1], m} y_{[1], m}-w y_{[1], m} .
$$


First order conditions imply an optimal price equal to;

$$
P_{[1], m}=\frac{w}{\alpha}
$$

and optimal output equal to;

$$
y_{[1], m}=Y A_{[1], m}\left(\frac{\alpha}{w}\right)^{\frac{1}{1-\alpha}} .
$$

Together, these imply an innovator with quality $A_{[1], m}$ earns operating profits for one period equal to;

$$
\pi_{[1], m}=Y A_{[1], m}(1-\alpha)\left(\frac{\alpha}{w}\right)^{\frac{\alpha}{1-\alpha}}
$$

Creators of original products earn similar profits for one period, equal to;

$$
\pi_{o}=Y A_{o}(1-\alpha)\left(\frac{\alpha}{w}\right)^{\frac{\alpha}{1-\alpha}}
$$

After the first period of production, the best firm in market $m$ (or the only firm, in the case of new markets) must compete with $N_{m}^{i m}$ imitators. Taking the output of imitators as given, the incumbent firm chooses $\hat{y}_{[1], m}$ to maximize operating profits;

$$
\begin{gathered}
\hat{\pi}_{[1], m}=\hat{P}_{m} \hat{y}_{[1], m}-w \hat{y}_{[1], m} \\
=Y^{1-\alpha} A_{[1], m}^{1-\alpha}\left(\hat{y}_{[1], m}+\sum_{n=1}^{N_{m}^{i m}} \hat{y}_{n, m}\right)^{\alpha-1} \hat{y}_{[1], m}-w \hat{y}_{[1], m} .
\end{gathered}
$$

Taking for granted the fact that imitators face the same problem as the best firm, first order conditions imply the following optimal output for each competitor;

$$
\hat{y}_{m}=\frac{Y A_{[1], m}\left(N_{m}^{i m}+\alpha\right)^{\frac{1}{1-\alpha}}}{w^{\frac{1}{1-\alpha}}\left(N_{m}^{i m}+1\right)^{\frac{2-\alpha}{1-\alpha}}},
$$


and the following operating profits;

$$
\hat{\pi}_{m}=\frac{Y A_{[1], m}\left(N_{m}^{i m}+\alpha\right)^{\frac{\alpha}{1-\alpha}}(1-\alpha)}{w^{\frac{\alpha}{1-\alpha}}\left(N_{m}^{i m}+1\right)^{\frac{2-\alpha}{1-\alpha}}} .
$$

The price in a market with imitators can now be expressed as;

$$
\hat{P}_{m}=w\left(\frac{N_{m}^{i m}+1}{N_{m}^{i m}+\alpha}\right),
$$

which reduces to equation 1 if the number of imitators is zero.

The value of introducing an improved product into market $m$ in period $t$ can now be expressed as;

$$
\begin{gathered}
V_{m, t}^{s}=-\frac{Y_{t}}{L} \cdot \Psi_{m, t-2} \cdot c_{s} \cdot \rho+\frac{1}{N_{m}^{i n n}}\left(\mathbb{E}\left(\pi_{[1], m, t}\right)+\frac{\mathbb{E}\left(\hat{\pi}_{m, t+1}\right)}{1+r}\right) \\
-\frac{Y_{t+2}}{L} \cdot \frac{\Psi_{m, t} \cdot c_{s}^{\prime}(1-\lambda)}{(1+r)^{2} N_{m}^{i n n}}+\frac{(1-\lambda)}{(1+r)^{2}\left(N_{m}^{i n n}\right)^{2}}\left(\mathbb{E}\left(\pi_{[1], m, t+2}\right)+\frac{\mathbb{E}\left(\hat{\pi}_{m, t+3}\right)}{1+r}\right) \\
-\frac{Y_{t+4}}{L} \cdot \frac{\Psi_{m, t+2} \cdot c_{s}^{\prime}(1-\lambda)^{2}}{(1+r)^{4}\left(N_{m}^{i n n}\right)^{2}}+\frac{(1-\lambda)^{2}}{(1+r)^{4}\left(N_{m}^{\text {inn }}\right)^{3}}\left(\mathbb{E}\left(\pi_{[1], m, t+4}\right)+\frac{\mathbb{E}\left(\hat{\pi}_{m, t+5}\right)}{1+r}\right)+\ldots,
\end{gathered}
$$

where $c_{s}$ is the fixed cost of introducing an improved product for a new sequential innovator in the absense of patent protection, $c_{s}^{\prime}$ the same for the incumbent, $\rho$ the factor difference in fixed costs due to protection, and $1 / N^{i n n}$ the probability of having the highest-quality product. The lack of a time subscript on $r$ and $N^{i n n}$ reflects the fact that these variables will be constant along the BGP. The expectations operator on current and future profits reflects the fact that an innovator is uncertain about its quality draw. The presence of future rounds of innovation in equation 2 accounts for the probability $\left(N^{i n n}\right)^{k / 2}$ that the firm with the highest quality in period $t$ will repeatedly draw the highest quality every two periods up to and including in period $t+k$. 
The value of creating an original product at time $t$ can be expressed as;

$$
\begin{gathered}
V_{m, t}^{o}=-\frac{Y_{t}}{L} \cdot c_{o} \cdot \rho^{\phi}+\mathbb{E}\left(\pi_{[1], m, t}\right)+\frac{\mathbb{E}\left(\hat{\pi}_{m, t+1}\right)}{1+r} \\
-\frac{Y_{t+2}}{L} \cdot \frac{\Psi_{m, t} \cdot c_{s}^{\prime}(1-\lambda)}{(1+r)^{2}}+\frac{(1-\lambda)}{(1+r)^{2} N_{m}^{i n n}}\left(\mathbb{E}\left(\pi_{[1], m, t+2}\right)+\frac{\mathbb{E}\left(\hat{\pi}_{m, t+3}\right)}{1+r}\right) \\
-\frac{Y_{t+4}}{L} \cdot \frac{\Psi_{m, t+2} \cdot c_{s}^{\prime}(1-\lambda)^{2}}{(1+r)^{4} N_{m}^{i n n}}+\frac{(1-\lambda)^{2}}{(1+r)^{4}\left(N_{m}^{i n n}\right)^{2}}\left(\mathbb{E}\left(\pi_{[1], m, t+4}\right)+\frac{\mathbb{E}\left(\hat{\pi}_{m, t+5}\right)}{1+r}\right)+\ldots
\end{gathered}
$$

An imitator that enters a market with a copy of an incumbent's product can expect operating profits for only one period. The value of introducing an imitation into market $m$ in period $t$ can be expressed as;

$$
\hat{V}_{m, t}=-\frac{Y_{t}}{L} \cdot \Psi_{m, t-1} \cdot \hat{c} \cdot \rho^{\gamma}+\hat{\pi}_{m, t}
$$

where $\hat{c}$ is the fixed cost of introducing an imitation in the absense of patent protection, and $\rho^{\gamma}$ the factor difference in fixed costs due to protection.

Finally, I assume each firm operates in only one product market, thus allowing the number of firms in the economy to be pinned down.

\subsubsection{Stationary Decentralized Equilibrium}

A stationary decentralized equilibrium is a constant number of innovators per market $N^{i n n}$, imitators per market $N^{i m}$, product markets $M$, and markups over marginal cost before imitation $P / w$, and after imitation $\hat{P} / w$, as well as a constant growth rate $g$ of final-good output $Y$, and the wage rate $w$, such that the following conditions are satisfied:

(i) Consumer Optimization: $r=\frac{1+g}{\beta}-1$

(ii) Final-Good Firm Optimization: $P_{m}=\left(\frac{Y A_{[1], m}}{y_{[1], m}}\right)^{1-\alpha}$ and $\hat{P}_{m}=\left(\frac{Y A_{[1], m}}{\hat{y}_{m}\left(1+N_{m}^{i m}\right)}\right)^{1-\alpha}$ 
(iii) Intermediate Producer Optimization: $\frac{P_{m}}{w}=\frac{1}{\alpha}$ and $\frac{\hat{P}_{m}}{w}=\frac{N_{m}^{i m}+1}{N_{m}^{i m}+\alpha}$

(iv) Free Entry: $V^{o}=V_{m}^{s}=\hat{V}_{m}=0$

(v) Market Clearing (Goods): $Y=\left(\int_{0}^{M} A_{[1], m}^{1-\alpha} y_{[1], m}^{\alpha} d m\right)^{\frac{1}{\alpha}}$

(vi) Market Clearing (Labor): $L=\int_{0}^{M} y_{[1], m} d m$

where conditions (ii) through (iv) are understood to hold for all $m \in M$.

To solve for the stationary equilibrium I start with the market clearing conditions. In each period, half of all markets feature innovations and half feature identical competitors. Continue to let $M^{i n n} \subset M$ denote the subset of product markets in which innovation occurs in the current period, indexed by $m^{i n n}$, and let $M^{i m} \subset M$ denote the subset of product markets in which imitation occurs in the current period, indexed by $m^{i m}$. Substituting the optimal output of each producer $\left(y_{[1], m^{i n n}}\right.$ and $\left.\hat{y}_{m^{i m}}\right)$ results in the following expressions;

$$
w=M^{\frac{1-\alpha}{\alpha}}\left[L^{\prime}\right]^{\frac{1-\alpha}{\alpha}} \quad \text { and } \frac{Y}{L}=M^{\frac{1-\alpha}{\alpha}} \frac{\left[L^{\prime}\right]^{\frac{1}{\alpha}}}{\left[Y^{\prime}\right]},
$$

$$
\text { where } \begin{aligned}
{\left[{ }_{L^{\prime}}\right] } & \equiv \frac{1}{2} \cdot\left[\alpha^{\frac{\alpha}{1-\alpha}} \bar{A}_{[1]}^{i n n}+\left(\frac{N^{i m}+\alpha}{N^{i m}+1}\right)^{\frac{\alpha}{1-\alpha}} \bar{A}_{[1]}^{i m}\right], \\
{\left[Y^{\prime}\right] } & \equiv \frac{1}{2} \cdot\left[\alpha^{\frac{1}{1-\alpha}} \bar{A}_{[1]}^{i n n}+\left(\frac{N^{i m}+\alpha}{N^{i m}+1}\right)^{\frac{1}{1-\alpha}} \bar{A}_{[1]}^{i m}\right], \\
\bar{A}_{[1]}^{k} & \equiv \frac{1}{M^{k}} \int_{0}^{M^{k}} A_{[1], m^{k}} d m^{k}, \quad k \in\{i n n, i m\}
\end{aligned}
$$

and the quality of original products $A_{o}$ is understood to be equal to $\bar{A}_{[1]}^{i n n}$.

Given the assumptions made about each market's best quality in period zero, $\bar{A}_{[1], t}^{i n n}=\bar{A}_{[1], t}^{i m}$. $\left(1+\mathbb{E}\left[h_{[1]}\right]\right)^{1 / 2}$ and $\bar{A}_{[1], t}^{i m}=\left(1+\mathbb{E}\left[h_{[1]}\right]\right)^{t / 2}$, for all $t$. The wage and aggregate output per 
capita can therefore be expressed as;

$$
\begin{aligned}
& \left.w=M^{\frac{1-\alpha}{\alpha}}{ }_{L}\right]^{1-\alpha}\left(\bar{A}_{[1]}^{i m}\right)^{\frac{1-\alpha}{\alpha}} \text { and } \frac{Y}{L}=M^{\frac{1-\alpha}{\alpha}} \frac{[L]^{\frac{1}{\alpha}}}{[Y]}\left(\bar{A}_{[1]}^{i m}\right)^{\frac{1-\alpha}{\alpha}}, \\
& \text { where }\left[{ }_{L}\right] \equiv \frac{1}{2} \cdot\left[\alpha^{\frac{\alpha}{1-\alpha}}\left(1+\mathbb{E}\left[h_{[1]}\right]\right)^{1 / 2}+\left(\frac{N^{i m}+\alpha}{N^{i m}+1}\right)^{\frac{\alpha}{1-\alpha}}\right] \\
& \text { and } \quad[Y] \equiv \frac{1}{2} \cdot\left[\alpha^{\frac{1}{1-\alpha}}\left(1+\mathbb{E}\left[h_{[1]}\right]\right)^{1 / 2}+\left(\frac{N^{i m}+\alpha}{N^{i m}+1}\right)^{\frac{1}{1-\alpha}}\right]
\end{aligned}
$$

Both the measure of product markets $M$ and the expected value of the best innovation $\mathbb{E}\left[h_{[1]}\right]$ in each period are constant, so the growth rate $g$ depends only on $\mathbb{E}\left[h_{[1]}\right]$, which in turn depends on the number of sequential innovators per market $N^{i n n}$;

$$
1+g=\frac{Y_{t}}{Y_{t-1}}=\left(\frac{\bar{A}_{[1], t}^{i m}}{\bar{A}_{[1], t-1}^{i m}}\right)^{\frac{1-\alpha}{\alpha}}=\left(1+\mathbb{E}\left[h_{[1]}\right]\right)^{\frac{1-\alpha}{2 \alpha}}
$$

With expressions for $Y, w$, and $g$ in hand, the equilibrium number of product markets $M$, sequential innovators $N^{i n n}$, and imitators $N^{i m}$ can be solved for implicitly using the free-entry conditions (iv);

$$
\begin{gathered}
\text { imitators: } \hat{c} \rho^{\gamma}=\frac{L(1-\alpha)\left(N^{i m}+\alpha\right)^{\frac{\alpha}{1-\alpha}}}{M[L]\left(N^{i m}+1\right)^{\frac{2-\alpha}{1-\alpha}}}, \\
\text { sequential: } \quad c_{s} \rho+\frac{c_{s}^{\prime} \beta^{2}(1-\lambda)}{\left[N^{i n n}-\beta^{2}(1-\lambda)\right]} \\
=\frac{L(1-\alpha)}{M[L]\left[N^{i n n}-\beta^{2}(1-\lambda)\right]} \cdot\left[\alpha^{\frac{\alpha}{1-\alpha}}+\frac{\beta\left(N^{i m}+\alpha\right)^{\frac{\alpha}{1-\alpha}}}{(1+g)^{\frac{\alpha}{1-\alpha}}\left(N^{i m}+1\right)^{\frac{2-\alpha}{1-\alpha}}}\right],
\end{gathered}
$$




$$
\begin{gathered}
\text { original: } \quad c_{o} \rho^{\phi}+\frac{c_{s}^{\prime} \beta^{2}(1-\lambda) N^{i n n}}{\left[N^{i n n}-\beta^{2}(1-\lambda)\right]} \\
=\frac{L(1-\alpha) N^{i n n}}{M[L]\left[N^{i n n}-\beta^{2}(1-\lambda)\right]} \cdot\left[\alpha^{\frac{\alpha}{1-\alpha}}(1+g)^{\frac{\alpha}{1-\alpha}}+\frac{\beta\left(N^{i m}+\alpha\right)^{\frac{\alpha}{1-\alpha}}}{(1+g)^{\frac{\alpha}{1-\alpha}}\left(N^{i m}+1\right)^{\frac{2-\alpha}{1-\alpha}}}\right] .
\end{gathered}
$$

Given some distribution for $h_{i}$, the random variable determining each innovator's quality, all other variables are functions of $N^{i m}, N^{i n n}$, and $M$.

\subsection{Theoretical Results}

Here I examine how the stationary equilibrium of the economy depends on a number of exogenous variables. I start by discussing the effects of patent protection.

\subsubsection{Patent Protection}

By combining the free entry conditions for sequential and original innovators (equations 4 and 5), I can solve for the number of sequential innovators per market $N^{i n n}$;

$$
N^{i n n}=\left(\frac{c_{o}}{c_{s}}\right) \rho^{\phi-1} .
$$

Notice that equation 6 contains no trace of imitation. To the extent that patent protection affects imitation, this changes the value of entry equally for both original and sequential innovators. This change will be fully offset by a change in the number of markets $M$, brought about by a change in the number of original innovators, thus leaving the incentives for sequential innovators unchanged. If patent protection increases costs for both original and sequential innovators in the same proportion $(\phi=1)$, then both $N^{i n n}$ and the long-run growth rate of the economy are independent of the strength of patent protection. In this case, patent protection directly reduces the value of entry by the same factor for both original and sequential 
innovators. Using the same intuition as above, this reduction in the value of entry will be fully offset by a change in the number of original innovators. If patent protection increases the cost of sequential innovation more than original innovation $(\phi<1)$, then both the number of sequential innovations per market and the long-run growth rate will decrease. If $\phi>1$, then the opposite will be true.

Even if the strength of patent protection does not affect the growth rate along the BGP, it still affects the level of aggregate output. To understand how, consider first the case where the additional costs imposed by protection are the same for both original innovators and imitators $(\gamma=\phi)$, and assume for the moment that $N^{i n n}$ is fixed. The free entry condition for original innovators (5) shows that any increase in protection $\rho$ will be exactly offset by a decrease in the number of markets $M$, given some fixed number of imitators $N^{i m}$. If $\rho^{\phi} \cdot M$ is constant and equal to $\rho^{\gamma} \cdot M$, then the free entry condition for imitators (3) implies that $N^{i m}$ will indeed stay constant. An increase in patent protection must therefore reduce the number of markets, the number of firms, aggregate output, and welfare, while leaving unchanged the (long-run) growth rate, the number of imitators, and markups. The intuition for why protection does not affect imitation here is similar to that above. An increase in the cost of original innovation (due to patent protection) results in a lower equilibrium number of markets. This increases the size of each market just enough to offset the higher cost of imitation (when $\gamma=\phi$ ), so that the incentive to imitate is left unchanged. If $\phi \neq 1$ then $N^{i n n}$ and the growth rate will change (as explained above), moving the number of imitators $N^{i m}$ in the opposite direction.

If $\gamma$ is greater than $\phi$, that is, if patent protection increases costs for imitators more than for original innovators, then the number of imitators per market $N^{i m}$ is decreasing in the strength of patent protection $\rho$ (for a given $N^{i n n}$ ). As a result, markups are higher, which increases the return to innovation (the last terms in equations 4 and 5). This will offset the additional costs of innovation, so that the net effect of stronger patent protection on original innovation is ambiguous. Protection is more likely to increase original innovation the higher is $\gamma$. An increase 
in innovation is also more likely if the number of imitators $N^{i m}$ is already low (say, because of a high cost of imitation $\hat{c}$ ). When $N^{i m}$ is already low, a further decrease has a large effect on both markups and on the patent holder's market share.

\subsubsection{Other}

It is clear from the free entry conditions (equations 3 through 5 ) that the number of product markets $M$ is linear in population $L$. A larger population does not increase the size of each market, and so the number of imitators, markups, growth, and the number of firms per worker are all independent of population. This is in stark contrast to every other model with endogenous markups, but consistent with the empirical evidence documented by Bento and Restuccia (2015).

A higher discount rate $\beta$ is associated with more innovation, and therefore a larger number of markets $M$. A higher $M$ shrinks the size of each market, so imitation is reduced. As a result, markups under imitation are higher. The growth rate is independent of $\beta$ (equation 6 ), as the

change in $M$ leaves the value of entry for sequential innovators unchanged. Note that these results do not imply that subsidies or taxes need affect markups. For example if a proportional tax were applied in equally to the costs of innovators and imitators, the result would be the same as an increase in $\rho$ when $\gamma=\phi=1 . M$ would decrease, but markups would remain constant.

\section{Quantitative Analysis}

In this section I quantify the impact of patent protection on an economy. A quantitative analysis is especially useful here given the ambiguity associated with the theoretical effects of patent protection in Section 2.5. The most important parameters required for this analysis are $\phi$ and 
$\gamma$, which determine the relative costs associated with patent protection for imitators, sequential innovators, and original innovators. Importantly, different ordinal rankings of $\phi, \gamma$, and one are associated with different effects of protection on markups, the number of firms in the economy, and the fraction of innovations that are original rather than sequential. Consider first the value of $\phi$. If $\phi=1$ then patent protection increases the costs of both sequential and original innovators proportionately, leaving the number of sequential innovators $N^{i n n}$ unchanged. If $\phi>1$ then $N^{i n n}$ will increase, and vice versa. In the model, the ratio of original to total innovations is;

$$
\frac{\# \text { original }}{\# \text { total innovations }}=\frac{\lambda}{\lambda+(1-\lambda) N^{\text {inn }}},
$$

where $\lambda / 2$ is the fraction of markets with original innovations, $(1-\lambda) / 2$ the fraction with sequential innovations, and $N^{i n n}$ the number of sequential innovations per market. This ratio depends solely on $N^{i n n}$, and the effect of patent protection on $N^{i n n}$ depends solely on $\phi$. To obtain a value for $\phi$ I look to cross-country panel data on the strength of patent protection and on the fraction of patents that are original. If this measure of originality is unrelated to patent protection, then I must conclude that $\phi=1$. If originality is increasing in patent protection, then the estimated coefficient on patent protection can be used along with other calibration targets to back out a lower implied value for $\phi$ (and vice versa). As I detail below, it turns out that the data is consistent with $\phi$ equal to one.

As a measure of patent protection I use the Ginarte-Park Patent Rights Index developed in Ginarte and Park (1997) and updated in Park (2008). ${ }^{9}$ Each country-year in the Index is given a continuous value from zero to five, with the index value increasing in coverage (the number of product-types protected), duration of protection, the scope of patent rights, and membership in international intellectual property treaties, while decreasing in the number of restrictions on patent rights (like compulsory licensing). The Index reports values for each country every five years from as early as 1960 to 2005 .

\footnotetext{
${ }^{9}$ The Ginarte-Park Index has been used widely. Some examples are Smith (2001), Branstetter, Fisman, and Foley (2006), and Antràs, Desai, and Foley (2009).
} 
For a measure of the fraction of patents that are original I use data from the NBER Patent Database (Hall, Jaffe, and Trajtenberg, 2001). The NBER database contains a measure of originality for each utility patent granted in the U.S. from 1973 to 1999. For each patent, data is available for country of origin, industry, and year of application. This measure of originality is constructed in such a way as to be higher when a patent application cites previous patents across a wide range of fields, and lower when it cites previous patents mainly within its own field. To construct a measure of the fraction of patents that are original for each countryindustry-year, I first calculate a threshold equal to the median originality value across patents originating from the U.S. in the same industry-year. ${ }^{10}$ I then construct my measure to be equal to the fraction of patents from a country-industry-year that have originality values higher than this threshold.

Table 1: Patent Protection and Originality

\begin{tabular}{lcccc}
\hline \multicolumn{5}{c}{ dependent variable: fraction of original patents } \\
& $(1)$ & $(2)$ & $(3)$ & $(4)$ \\
\hline Patent Index & -0.03 & -0.02 & 0.02 & 0.01 \\
& $(0.04)$ & $(0.04)$ & $(0.02)$ & $(0.02)$ \\
Openness & & -0.000 & & 0.001 \\
& & $(0.002)$ & & $(0.001)$ \\
Heritage Index & & 0.0012 & & 0.0006 \\
& & $(0.0008)$ & & $(0.0004)$ \\
Entry Barriers & & 0.003 & & $-0.0008^{* *}$ \\
& & $(0.0004)$ & & $(0.0003)$ \\
& & & & \\
\hline$R^{2}$ & 0.02 & 0.02 & 0.07 & 0.07 \\
observations & 4462 & 4345 & 4462 & 4345 \\
\hline
\end{tabular}

Notes: Originality of patents is from Hall, Jaffe, and Trajtenberg (2001), Patent Index is from Ginarte and Park (1997) and Park (2008), openness is from Penn World Tables v8, Heritage Index is from Heritage Foundation (2015), and entry barriers is from World Bank (2014). All regressions include time dummies, and all variables relative to the U.S. Robust standard errors in parantheses. ${ }^{* *}$ refers to a five percent level of significance.

Column 1 of Table 1 reports the result of an OLS regression of the ratio of original to total

\footnotetext{
${ }^{10}$ To make the NBER data comparable with the Ginarte-Park Index, I pool observations for each countryindustry across five-year intervals. For example, the measure of originality associated with the Patents Rights Index value for 1990 is constructed using patent data from 1988 to 1992. The word 'year' refers to this five-year interval.
} 
patents on the strength of patent protection (and time dummies). The coefficient on patent protection is negative, but statistically insignificant. This insignificance result is robust to the addition of other variables that could plausibly help explain the ratio of original to total patents. Column 2 reports the OLS estimates for patent protection, openness to trade, institutional quality (Heritage Index), and a measure of entry barriers. ${ }^{11}$ Columns 3 and 4 report the estimates from analogous regressions using analytic weights equal to the number of patents used to construct the originality measure for each country-industry-year. The estimated coefficients on patent protection are again insignificantly different from zero. Finally, using the median value for originality for U.S. patents as the threshold for each industry-year is somewhat arbitrary, so in Appendix A.1 I repeat this analysis using a threshold equal to the mean U.S. value, as well as directly using the originality measure from Hall, Jaffe, and Trajtenberg (2001) as a dependent variable. In all cases, the coefficient on patent protection is insignificant. Given these results, I conclude that patent protection increases the costs of original and sequential innovation proportionately. For the purposes of calibration, I therefore assume $\phi=1$.

I now turn to $\gamma$. If $\gamma=\phi=1$, then patent protection increases the costs of innovation and imitation proportionately, while $\gamma>\phi=1$ implies more protection from imitators. A higher $\gamma$ therefore implies a stronger effect of protection on the number of imitators entering each market and on average markups. To obtain a value for $\gamma$ I look to cross-country data on the strength of patent protection and on markups. If markups are unrelated to patent protection, then I must conclude that $\gamma$ is equal to one. If markups are increasing in patent protection, then the estimated coefficient on patent protection can be used along with other calibrated parameters in the model to back out a higher implied value for $\gamma$. As I detail below, it turns out that the data is consistent with $\gamma$ equal to one.

As a measure of patent protection I continue to use the Ginarte-Park Patent Rights Index

\footnotetext{
${ }^{11}$ Openess to trade is measured as imports plus exports as a fraction of GDP for each year covered by the Patent Index, reported in the Penn World Tables v8. Heritage Index is a measure of economic freedom, reported for 1995. Entry barriers are proxied by the regulatory cost of starting a formal business, as measured by the World Bank's Doing Business Surveys. For more details about these data see Feenstra, Inklaar, and Timmer (forthcoming), Heritage Foundation (2015), and World Bank (2014).
} 
(Ginarte and Park, 1997, and Park, 2008). For my measure of markups I use the inverse of the labor share, or the ratio of total value added to total labor compensation. By using only labor share, rather than the shares of both labor and capital, I am assuming that the relative price of capital to labor is uncorrelated with patent protection. ${ }^{12}$ Gollin (2002) argues convincingly that comparisons of labor shares across countries must take into account the implied wages of own-account workers, as they represent a substantial part of the workforce in less developed countries. To address this I use two different sources of labor share data. The first is from Gollin (2002), where the data is representative of all sectors and adjusted to account for own-account workers. This data is available for 26 countries included in the Ginarte-Park Index. Given the small number of usable countries, I also use labor share data from the World Bank's Enterprise Surveys. The Enterprise Surveys contain establishment-level data on sales, intermediate purchases, and inputs, and are constructed in such a way as to be comparable across countries and representative of establishments with at least five workers. The fact that this data excludes very small establishments should make labor shares comparable across countries. The World Bank has constructed two separate datasets, one with data for 2002-2005 and a second with data for 2006-2014. The earlier dataset contains data for 45 (usable) countries and up to 28 industries, while the later dataset contains 77 countries and 15 industries. For each country-industry I calculate markups as the ratio of total value-added to the total wage bill.

Table 2 shows the results of six regressions of markups on patent protection, two each using Gollin's (2002) data, the early World Bank (2015) data, and the later World Bank data. The first column of each suggest that markups are unrelated to patent protection, except for the coefficient estimate from the most recent World Bank data. In the second columns I include a measure of each country's openness to trade (described above) to address the fact that the Ginarte and Park Patent Rights Index allocates a higher index value to countries ratifying

\footnotetext{
${ }^{12}$ This seems to be the case. In a cross-country regression of the relative price of capital on both patent protection and GDP per capita in 2005, both coefficients are insignificant. Data for the relative price of capital and for GDP per capita in this analysis is taken from Penn World Tables v8, and the relative price of capital is calculated as in Restuccia and Urrutia (2001).
} 
Table 2: Patent Protection and Markups

\begin{tabular}{lcccccc}
\hline dependent variable: markups & \multicolumn{4}{c}{ World Bank } \\
& \multicolumn{2}{c}{ Gollin } & \multicolumn{3}{c}{$(2002-2005)$} & $(2006-2014)$ \\
& $(1)$ & $(2)$ & $(3)$ & $(4)$ & $(5)$ & $(6)$ \\
\hline Patent Index & -0.20 & -0.22 & -0.05 & 0.12 & $-0.72^{* * *}$ & -0.24 \\
& $(0.14)$ & $(0.18)$ & $(0.11)$ & $(0.12)$ & $(0.23)$ & $(0.29)$ \\
Openness & & 0.01 & & $-0.17^{* * *}$ & & $0.19^{* *}$ \\
& & $(0.01)$ & & $(0.05)$ & & $(0.09)$ \\
Heritage Index & & 0.11 & & -0.12 & & -0.06 \\
& & $(0.21)$ & & $(0.20)$ & & $(0.25)$ \\
Entry Barriers & & -0.00 & & $0.08^{* *}$ & & $0.23^{* * *}$ \\
& & $(0.03)$ & & $(0.04)$ & & $(0.04)$ \\
\hline$R^{2}$ & 0.15 & 0.19 & 0.11 & 0.16 & 0.04 & 0.10 \\
observations & 26 & 25 & 522 & 494 & 805 & 774 \\
\hline
\end{tabular}

Notes: All variables in logs. Gollin refers to markup data from Gollin (2002), World Bank refers to markup data from the World Bank's Enterprise Surveys. Columns 3 through 6 report estimates from regressions with industry dummies. Patent Index is from Park (2008). Openness is from Penn World Tables v8, Heritage Index is from Heritage Foundation (2015), and entry barriers is from World Bank (2014). Robust standard errors in parantheses. ${ }^{* * *}$ and ${ }^{* *}$ refer to one and five percent levels of significance.

international property rights treaties. Ratification of these treaties is often accompanied by, and even a condition for, entry into the World Trade Organization or other trade agreements which could themselves impact competition and markups. To otherwise control for differences in the quality of institutions and policies across countries, I include the Heritage Foundation's (2015) Economic Freedom Index and the World Bank's (2014) measure of entry barriers. Controlling for these other variables results in insignificant coefficient estimates for patent protection (pvalues all greater than 10 percent), even in the most recent data (Column 6).

The results in Table 2 suggest that an appropriate value for $\gamma$ is one. Given that patent protection therefore affects only the measure of markets $M$ in steady state, and not the growth rate or the number of imitators, the factor difference in output per capita between an economy 
with weak protection $\rho_{L}$ and strong protection $\rho_{H}$ can be expressed simply as;

$$
\frac{Y\left(\rho_{L}\right)}{Y\left(\rho_{H}\right)}=\left(\frac{M\left(\rho_{L}\right)}{M\left(\rho_{H}\right)}\right)^{\frac{1-\alpha}{\alpha}} .
$$

The Ginarte-Park Index is an index of the strength of patent protection, so it is not obvious how different index values can be mapped to $\rho$ in the model. But one of the implications of $\gamma=1$ is that differences in the number of firms (per worker) across countries caused by differences in patent protection imply differences in the number of product markets $M$ (per worker). In the model the number of firms is;

$$
\frac{M}{2}\left[\lambda+(1-\lambda) N^{i n n}+1+N^{i m}\right],
$$

where $M \cdot 1 / 2 \cdot \lambda$ is both the number of dying markets and the number ofl original innovators, $M \cdot 1 / 2 \cdot(1-\lambda)$ the number of surviving markets with sequential innovations, $N^{i n n}$ the number of sequential innovators per surviving market, $M \cdot 1 / 2$ the number of markets with imitators, and $1+N^{i m}$ the number of firms competing in each market with imitators. If $\phi=\gamma=1$ then differences in patent protection $\rho$ leave $N^{i n n}$ and $N^{i m}$ unchanged. Any factor difference in the number of firms (per worker) between two countries due to a difference in patent protection can therefore be interpreted as a factor difference in the number of markets $M$ (per worker).

To estimate the relationship between patent protection and the number of firms per worker I use data from Bento and Restuccia (2015), which reports the average number of workers per manufacturing establishment for 134 economies. Figure 1 plots the number of establishments per worker against the Ginarte-Park Index for 80 countries, and shows a clear negative relationship between the strength of patent protection and the number of establishments.

The number of establishments per worker can obviously differ across countries for reasons other than patent protection, so in Column 2 of Table 3 I report the results of a regression of establishments per worker on patent protection, openness to trade, and a measure of institutional 


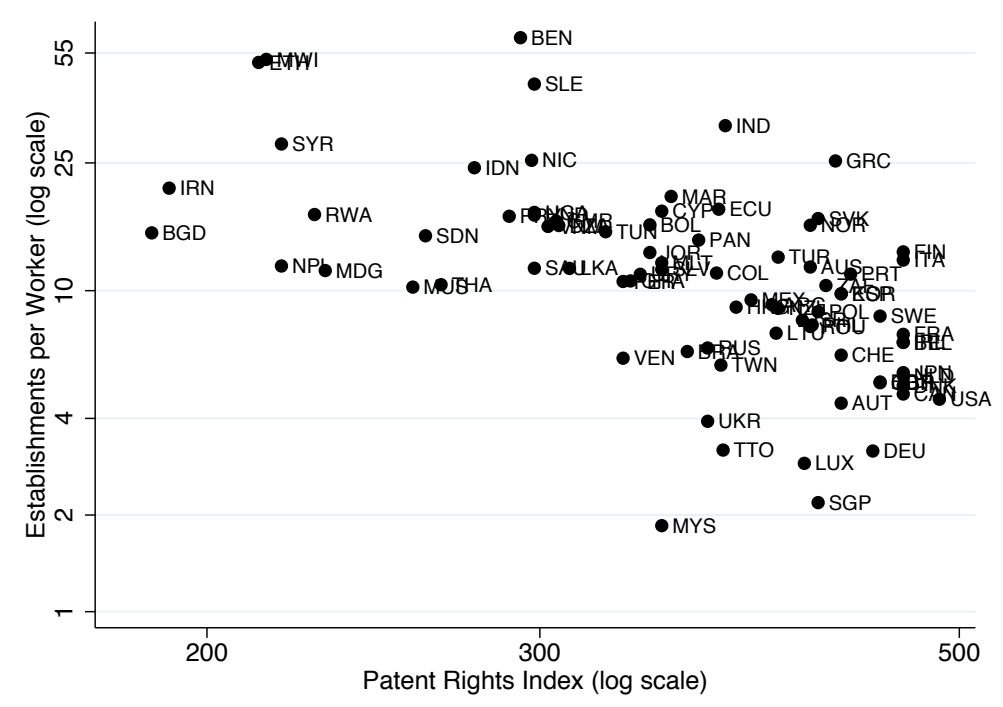

Figure 1: Number of Establishments and Patent Protection

quality. The coefficient estimate on the Ginarte-Park Index is -0.72 , implying an almost one percent drop in the number of firms from a one percent increase in the Index value. To quantify the effect on aggregate productivity from patent protection in the U.S., I first estimate the increase in the number of firms that would result if the U.S. reduced the strength of patent protection to the average level observed in the bottom decile of countries included in Column 2. For 2005, Park (2008) reports a value of 488 for the U.S. and an average value of 213 for the eight countries with the weakest protection. An elasticity of establishments with respect to protection of -0.72 implies that reducing protection would increase the number of establishments in the U.S. by a factor of $(213 / 488)^{-0.72}=1.82$. This implies an increase in aggregate productivity by a factor of $1.82^{\frac{1-\alpha}{\alpha}}$, where $1 /(1-\alpha)$ is the elasticity of substitution between product markets. Using a value of 5.5/6.5 for $\alpha$ (Imbs and Méjean, 2015), this implies that weakening patent protection in the U.S. would lead to a permanent increase in aggregate output by 11 percent. $^{13}$

\footnotetext{
${ }^{13}$ Imbs and Méjean (2015) suggest an elasticity of substitution of 6.5 for macroeconomic models that assume only one industry. This implies a value for $\alpha$ of 5.5/6.5.
} 


\section{Table 3: Number of Establishments and Patent Protection}

\begin{tabular}{lcc}
\hline \multicolumn{2}{l}{ dependent variable: manufacturing establishments per worker } \\
& $(1)$ & $(2)$ \\
\hline Patent Index & $-1.64^{* * *}$ & $-0.72^{* *}$ \\
& $(0.26)$ & $(0.31)$ \\
Openness & & $-0.18^{*}$ \\
& & $(0.11)$ \\
Heritage Index & 0.36 \\
& & $(0.54)$ \\
Entry Barriers & & $0.19^{* * *}$ \\
& 0.33 & $(0.55)$ \\
\hline$R^{2}$ & 80 & 0.46 \\
observations & & 75 \\
\hline
\end{tabular}

Notes: All variables in logs. Establishments per worker is from Bento and Restuccia (2015). Patent Index is from Park (2008), Openness is from Penn World Tables v8, Heritage Index is from Heritage Foundation (2015), and entry barriers is from World Bank (2014). Robust standard errors in parantheses. ${ }^{* * *},{ }^{* *}$, and ${ }^{*}$ refer to one, five, and ten percent levels of significance.

\section{Conclusion}

In this paper I develop a general equilibrium model that can generate any qualitative effect of patent protection on markups, imitation, long-run growth, and aggregate productivity. Calibrating the model to match the relationships between these variables found in the data, I am able to quantitatively assess the impact of reducing the strength of patent protection from its current level in the United States. The results are surprising, but are clearly implied by the data: no change in markups, imitation, or long-run growth, but a substantial increase in the number of firms and in aggregate productivity.

It is important to note that the analysis in this paper takes an aggregate view of the effects of patent protection. To the extent that the relative costs imposed by patent protection may differ across industries, different industries may react in different ways to protection. This implies that different levels of protection may be optimal across industries. But given the one-size-fitsall nature of current policy, the present model interprets the data as suggesting that substantial 
gains in productivity can be achieved by weakening patent protection. 


\section{A Appendix}

\section{A.1 Measures of Originality}

Here I try two other measures of originality. First, I duplicate the benchmark measure but use the mean score in the U.S. as the originality threshold for each industry-year. Second, I simply use the originality score from Hall, Jaffe, and Trajtenberg (2001), relative to the U.S. score for each industry-year. Tables 4 and 5 support the conclusion in Section 3 that patent protection does not induce a change in the number of sequential innovators per market.

Table 4: Patent Protection and Originality: U.S. Mean as Threshold

\begin{tabular}{lcccc}
\hline \multicolumn{4}{c}{ dependent variable: fraction of original patents } \\
& $(1)$ & $(2)$ & $(3)$ & $(4)$ \\
\hline Patent Index & -0.02 & -0.01 & 0.02 & 0.02 \\
& $(0.04)$ & $(0.04)$ & $(0.02)$ & $(0.02)$ \\
Openness & & -0.001 & & 0.0001 \\
& & $(0.002)$ & & $(0.0011)$ \\
Heritage Index & & 0.001 & & 0.0007 \\
& & $(0.001)$ & & $(0.0004)$ \\
Entry Barriers & & 0.0002 & & $-0.0009^{* * *}$ \\
& & $(0.0004)$ & & $(0.0003)$ \\
& & & & \\
\hline$R^{2}$ & 0.005 & 0.006 & 0.029 & 0.034 \\
observations & 4462 & 4369 & 4462 & 4347 \\
\hline
\end{tabular}

Notes: Originality of patents is from Hall, Jaffe, and Trajtenberg (2001), Patent Index is from Ginarte and Park (1997) and Park (2008), openness is from Penn World Tables v8, Heritage Index is from Heritage Foundation (2015), and entry barriers is from World Bank (2014). All regressions include time dummies, and all variables relative to the U.S. Robust standard errors in parantheses. ${ }^{* * *}$ refers to a one percent level of significance. 
Table 5: Patent Protection and Originality: Mean Originality

\begin{tabular}{|c|c|c|c|c|}
\hline \multicolumn{5}{|c|}{ dependent variable: mean originality } \\
\hline Patent Index & $\begin{array}{c}0.012 \\
(0.052)\end{array}$ & $\begin{array}{c}0.004 \\
(0.055)\end{array}$ & $\begin{array}{l}-0.002 \\
(0.032)\end{array}$ & $\begin{array}{l}-0.001 \\
(0.033)\end{array}$ \\
\hline Openness & & $\begin{array}{l}-0.0005 \\
(0.0029)\end{array}$ & & $\begin{array}{c}0.003 \\
(0.002)\end{array}$ \\
\hline Heritage Index & & $\begin{array}{c}0.002 \\
(0.001)\end{array}$ & & $\begin{array}{c}0.001 \\
(0.001)\end{array}$ \\
\hline Entry Barriers & & $\begin{array}{c}0.0001 \\
(0.0006)\end{array}$ & & $\begin{array}{c}-0.0016^{* * *} \\
(0.0005)\end{array}$ \\
\hline$R^{2}$ & 0.005 & 0.006 & 0.019 & 0.027 \\
\hline observations & 4460 & 4334 & 4460 & 4334 \\
\hline
\end{tabular}

Notes: Originality of patents is from Hall, Jaffe, and Trajtenberg (2001), Patent Index is from Ginarte and Park (1997) and Park (2008), openness is from Penn World Tables v8, Heritage Index is from Heritage Foundation (2015), and entry barriers is from World Bank (2014). All regressions include time dummies, and all variables relative to the U.S. Robust standard errors in parantheses. ${ }^{* * *}$ refers to a one percent level of significance.

\section{References}

[1] Acemoglu, Daron, and Ufuk Akcigit, "Intellectual Property Rights Policy, Competition and Innovation," Journal of the European Economic Association, 10 (2012), 1-42.

[2] Antràs, Pol, Mihir A. Desai, and C. Fritz Foley, "Multinational Firms, FDI Flows, and Imperfect Capital Markets," Quarterly Journal of Economics, 124 (2009), 1171-1219.

[3] Bento, Pedro, "Competition as a Discovery Procedure: Schumpeter Meets Hayek in a Model of Innovation," American Economic Journal: Macroeconomics, 6 (2014),124-152 .

[4] Bento, Pedro and Diego Restuccia, "Misallocation, Establishment Size, and Productivity," University of Toronto Working Paper, 537 (2015).

[5] Bessen, James and Erik Maskin, "Sequential Innovation, Patents, and Imitation," RAND Journal of Economics, 40 (2009), 611-635.

[6] Bhattacharya, Dhritiman, Nezih Guner, and Gustavo Ventura, "Distortions, Endogenous 
Managerial Skills and Productivity Differences," Review of Economic Dynamics, 16 (2013), $11-25$.

[7] Boldrin, Michele and David K. Levine, Against Intellectual Monopoly (Cambridge: Cambridge University Press, 2008).

[8] Boldrin, Michele and David K. Levine, "The Case Against Patents," Journal of Economic Perspectives, 27 (2013), 3-22.

[9] Bollard, Albert, Peter J. Klenow, and Huiyu Li, "Entry Costs Rise with Development," manuscript, (2014).

[10] Branstetter, Lee G., Raymond Fisman, and C. Fritz Foley, "Do Stronger Intellectual Property Rights Increase International Technology Transfer? Empirical Evidence from U.S. Firm-Level Panel Data," Quarterly Journal of Economics, 121 (2006), 321-349.

[11] Chu, Angus C., Guido Cozzi, and Silvia Galli, "Does Intellectual Monopoly Stimulate or Stifle Innovation?" European Economic Review, 56 (2012), 727-746.

[12] Desmet, Klaus and Stephen L. Parente, "Bigger is Better: Market Size, Demand Elasticity, and Innovation" International Economic Review, 51 (2010), 319-333.

[13] Edmond, Chris, Virgiliu Midrigan, and Daniel Xu, "Competition, Markups and the Gains from International Trade" American Economic Review, (forthcoming).

[14] Feenstra, Robert C., Robert Inklaar, and Marcel P. Timmer, "The Next Generation of the Penn World Table," American Economic Review, (forthcoming).

[15] Ginarte, Juan C. and Walter G. Park, "Determinants of Patent Rights: A Cross-National Study," Research Policy, 26 (1997), 283-301

[16] Gollin, Douglas, "Getting Labor Shares Right," Journal of Political Economy, 110 (2002), 458-474. 
[17] Grossman, Gene M. and Elhanan Helpman, "Quality Ladders in the Theory of Growth," Review of Economic Studies, 58 (1991), 43-61.

[18] Hall, Bronwyn H., Adam Jaffe, and Manuel Trajtenberg, "The NBER Patent Citations Data File: Lessons, Insights and Methodological Tools," NBER Working Papers, 8498 (2001).

[19] Helpman, Elhanan, "Innovation, Imitation, and Intellectual Property Rights," Econometrica, 61 (1993), 1247-1280.

[20] Heritage Foundation, The, The Index of Economic Freedom, online (2015).

[21] Hopenhayn, Hugo, Gerard Llobet, and Matthew Mitchell, "Rewarding Sequential Innovators: Prizes, Patents, and Buyouts," Journal of Political Economy, 114 (2006), 1041-1068.

[22] Hsieh, Chang-Tai and Peter J. Klenow, "The Life Cycle of Plants in India and Mexico," Quarterly Journal of Economics, 129 (2014), 1035-1084.

[23] Imbs, Jean and Isabelle Méjean, "Elasticity Optimism," American Economic Journal: Macroeconomics, 7 (2015), 43-83.

[24] Lerner, Josh, "The Empirical Impact of Intellectual Property Rights on Innovation: Puzzles and Clues," American Economic Review, Papers and Proceedings, 99 (2009), 343-348.

[25] Mansfield, Edwin, Mark Schwartz, and Samuel Wagner, "Imitation Costs and Patents: An Empirical Study," Economic Journal, 91 (1981), 907-918.

[26] Melitz, Marc J. and Giancarlo P. Ottaviano, "Market Size, Trade, and Productivity," Review of Economic Studies, 75 (2008), 295-316.

[27] Moser, Petra, "Patents and Innovation: Evidence from Economic History," Journal of Economic Perspectives, 27 (2013), 23-44.

[28] Moser, Petra and Alessandra Voena, "Compulsory Licensing: Evidence from the Trading with the Enemy Act," American Economic Review, 102 (2012), 396-427. 
[29] O'Donoghue, Ted and Josef Zweimüller, "Patents in a Model of Endogenous Growth," Journal of Economic Growth, 9 (2004), 81-123.

[30] Park, Walter G., "International Patent Protection: 1960-2005," Research Policy, 37 (2008), 761-766.

[31] Peters, Michael, "Heterogeneous Mark-Ups, Growth and Endogenous Misallocation," manuscript, (2013).

[32] Qian, Yi, "Do National Patent Laws Stimulate Domestic Innovation in a Global Patenting Environment? A Cross-Country Analysis of Pharmaceutical Patent Protection, 1978-2002," Review of Economics and Statistics, 89 (2007), 436-453.

[33] Restuccia, Diego and Carlos Urrutia, "Relative Prices and Investment Rates," Journal of Monetary Economics, 47 (2001), 93-121.

[34] Sakakibara, Mariko and Lee Branstetter, "Do Stronger Patents Induce More Innovation? Evidence from the 1988 Japanese Patent Law Reforms," RAND Journal of Economics, 32 (2001), 77-100.

[35] Scotchmer, Suzanne, "Standing on the Shoulders of Giants: Cumulative Research and the Patent Law," Journal of Economic Perspectives, 5 (1991), 29-41.

[36] Segerstrom, Paul, "Innovation, Imitation, and Economic Growth," Journal of Political Economy, 99 (1991), 807-827.

[37] World Bank, Doing Business 2015: Going Beyond Efficiency (Washington, DC: World Bank Group, 2014).

[38] World Bank, The, Enterprise Surveys, online (2015).

[39] Zander, Udo and Bruce Kogut, "Knowledge and the Speed of the Transfer and Imitation of Organizational Capabilities: An Empirical Test," Organization Science, 6 (1995), 76-92. 